\title{
Experimental study of arsenic removal by direct contact membrane distillation
}

\author{
Dan Qu, Jun Wang, Deyin Hou, Zhaokun Luan*, Bin Fan, Changwei Zhao
}

State Key Laboratory of Environmental Aquatic Chemistry, Research Center for Eco-Environmental Sciences,

The Chinese Academy of Sciences, P.O. Box 2871, 100085 Beijing, China

\section{A R T I C L E I N F O}

Article history:

Received 29 February 2008

Received in revised form 3 June 2008

Accepted 8 July 2008

Available online 16 July 2008

\section{Keywords:}

Arsenic removal

Direct contact membrane distillation

Water treatment

Groundwater

\begin{abstract}
A B S T R A C T
Arsenite $(\mathrm{As}(\mathrm{III}))$ and arsenate $(\mathrm{As}(\mathrm{V}))$ removal by direct contact membrane distillation (DCMD) were investigated with self-made polyvinylidene fluoride (PVDF) membranes in the present work. Permeability and ion rejection efficiency of the membrane were tested before the arsenic removal experiments. A maximum permeate flux $20.90 \mathrm{~kg} / \mathrm{m}^{2} \mathrm{~h}$ was obtained, and due to the hydrophobic property, the PVDF membrane had high rejection of inorganic anions and cations which was independent of the solution $\mathrm{pH}$ and the temperature. The experimental results indicated that DCMD process had higher removal efficiency of arsenic than pressure-driven membrane processes, especially for high-concentration arsenic and arsenite removal. The experimental results indicated that the permeate $\mathrm{As}(\mathrm{III})$ and $\mathrm{As}(\mathrm{V})$ were under the maximum contaminant limit $(10 \mu \mathrm{g} / \mathrm{L})$ until the feed $\mathrm{As}(\mathrm{III})$ and $\mathrm{As}(\mathrm{V})$ achieved 40 and $2000 \mathrm{mg} / \mathrm{L}$, respectively. The $250 \mathrm{~h}$ simultaneous DCMD performance of $0.5 \mathrm{mg} / \mathrm{L} \mathrm{As}(\mathrm{III})$ and $\mathrm{As}(\mathrm{V})$ solution was carried out, respectively. The permeate arsenic was not detected during the process which showed the PVDF membrane had stable arsenic removal efficiency. Membrane morphology changed slightly after the experiments, however, the permeability and the ion rejection of the membrane did not change.
\end{abstract}

(C) 2008 Elsevier B.V. All rights reserved.

\section{Introduction}

Arsenic is present in water as a result of both natural and anthropogenic activities. Inorganic arsenic occurs in the environment in several forms. In natural waters, $\mathrm{As}(\mathrm{III})$ and $\mathrm{As}(\mathrm{V})$ are generally considered to be the dominant species. Arsenic contamination of groundwater has become one of the most serious problems in water environment, and it is particularly problematic when the groundwater is utilized as drinking water [1].

Exposure to arsenic contaminated water can lead to a number of health problems. Usually arsenic is built up in the body through drinking water, food contaminated with arsenic, and causes increased risks of cancer in the skin, lungs, liver, kidneys, and bladder. Consumption of arsenic also leads to disturbances of the cardiovascular and nervous system functions which eventually lead to death [2]. A new standard for arsenic in drinking water at $10 \mu \mathrm{g} / \mathrm{L}$ was adopted in China recently, which was in accordance with the maximum contaminant level of arsenic in drinking water recommended by WHO [3].

The methods developed for arsenic removal are mainly precipitation [4], ion-exchange [5], adsorption [6], and membrane processes [7]. To effectively decrease arsenic by precipitation requires a large amount of chemicals. This process also creates vol-

\footnotetext{
* Corresponding author. Tel.: +86 10 62849150; fax: +861062849150.

E-mail addresses: luanzk@rcees.ac.cn, luanzk@mail.rcees.ac.cn (Z. Luan).
}

umetric sludge, which needs further treatments before disposing it into the environment. Ion-exchange process has a disadvantage of releasing noxious chemical reagents used in the resin regeneration into the environment. Adsorption was considered to be an efficient way to remove arsenic from natural waters and wastewaters [6]. Activated carbon [8], oxides [9,10], biosorbents [11] and other lowcost adsorbents [12-14] were used for arsenic removal. However, the adsorption method requires a regeneration process after the adsorbents being exhausted, which may decrease the capacity of adsorbents.

Reverse osmosis and nanofiltration are two common pressuredriven membrane processes used for arsenic removal. The experimental results showed high removal efficiency of $\mathrm{As}(\mathrm{V})$ but very low removal efficiency of $\mathrm{As}(\mathrm{III})$ for both the two membrane processes, especially for the nanofiltration. Furthermore, the removal efficiency of arsenic by reverse osmosis and nanofiltration are strongly influenced by the solution $\mathrm{pH}$ and the kinds of membranes [15-19]. Here, a hydrophobic membrane process-membrane distillation was presented for arsenic removal.

Membrane distillation (MD) is a thermally driven process that involves transport of water vapor through a porous hydrophobic membrane. During the MD process of solutions with non-volatile solutes, only water vapor can transfer through the membrane. Thus, theoretically speaking, the MD process enables the production of pure water from natural water. Compared with the pressure-driven membrane processes, membrane distillation is less dependent on the initial salinity of the feed as well as a higher salt rejection ratio 
[20]. Thus, membrane distillation has been used in seawater desalination [21], juice concentration [22], and other industrial areas [23-25]. However, membrane distillation has little been used for arsenic removal.

Direct contact membrane distillation (DCMD) is one of the four basic configurations of MD, in which the feed and the permeate are directly separated by the membrane. And DCMD is considered to be the most simple, economical and efficient configuration [26]. Thus, in the presented work, DCMD was used for arsenic removal. Both the removal of $\mathrm{As}(\mathrm{III})$ and $\mathrm{As}(\mathrm{V})$ were investigated.

\section{Materials and methods}

\subsection{Reagents and analysis methods}

All chemicals used in the experiments were of analytical reagent grade. $\mathrm{As}_{2} \mathrm{O}_{3}$ and $\mathrm{Na}_{2} \mathrm{HAsO}_{3} \cdot 7 \mathrm{H}_{2} \mathrm{O}$ were obtained from E. Merck (Darmstadt, Germany). As(III) and As(V) solutions were prepared with tap water (Beijing, no. 9 plant), respectively. And the other solutions were prepared with deionized water.

The conductivity of the feed was measured using a conductivitymeter (CO150, HACH, USA). Analysis of $\mathrm{Cl}^{-}$and $\mathrm{SO}_{4}{ }^{2-}$ were made by ion chromatograph (861, Metrohm, Switzerland), respectively. $\mathrm{Ca}^{2+}$ was analyzed using EDTA titration method. Arsenic analysis was performed by hydrid-generation atomic fluorescence spectrometry (HG-AFS) (AF-610, Rayleigh, China), following the reduction of $\mathrm{As}(\mathrm{V})$ to $\mathrm{As}(\mathrm{III})$. And the reducing agents were thiourea and ascorbic acid.

\subsection{Membranes and DCMD unit}

The hydrophobic polyvinylidene fluoride (PVDF) capillary membranes used in the experiments were self-made and the characteristics are shown in Table 1.

The DCMD experimental installation is shown in Fig. 1. It consisted of two thermostatic cycles, the feed one, and the permeate one, which were connected to the membrane module. The membrane module with the diameter of $0.015 \mathrm{~m}$ and the effective length

Table 1

Membrane characteristics

\begin{tabular}{ll}
\hline$d_{\text {out }} / d_{\text {in }}{ }^{\mathrm{a}}(\mu \mathrm{m})$ & $1 / 0.8$ \\
$\varepsilon^{\mathrm{b}}(\%)$ & 80 \\
Average pore radius $(\mu \mathrm{m})$ & 0.15 \\
$\delta^{\mathrm{c}}(\mathrm{mm})$ & 0.20 \\
$\mathrm{LEPw}^{\mathrm{d}}(\mathrm{kPa})$ & 250 \\
\hline
\end{tabular}

a Outside/inside diameter of the capillary membrane.

b Porosity.

c Membrane thickness.

d Liquid entry pressure of water.

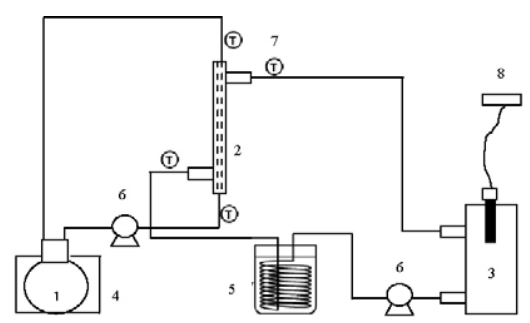

Fig. 1. DCMD setup: (1) feed reservoir; (2) membrane module, (3) permeate reservoir, (4) water bath, (5) cooling coil, (6) pump, (7) thermometer and (8) conductivity monitor. of $0.10 \mathrm{~m}$ was assembled in a vertical position. The module was equipped with 50 hydrophobic PVDF membranes, and the total effective area of the module was calculated for the internal capillary diameter and amounted to $12.56 \times 10^{-4} \mathrm{~m}^{2}$. Both the feed and the permeate were pumped from the bottom to the upper part of the module. The feed flowed inside the capillaries, whereas the permeate flowed through the intertubular space. There were four thermometers equipped on the inlets and the outlets of the feed side and the permeate side, respectively. The permeate flux was measured by the overflow volume of the permeate reservoir.

\subsection{Permeability and ion rejection tests}

To investigate the water vapor permeability of the membrane, a set of experiments were carried out using pure water as feed. The mean feed temperature varied from 40 to $70^{\circ} \mathrm{C}$ while the permeate temperature was kept at $20^{\circ} \mathrm{C}$. Besides, at each feed temperature, the permeate fluxes were also measured in a range of feed flow rate $\left(V_{\mathrm{f}}\right)$ from 0.23 to $0.96 \mathrm{~m} / \mathrm{s}$. The permeate flow rate $\left(V_{\mathrm{p}}\right)$ was kept at $0.10 \mathrm{~m} / \mathrm{s}$.

To investigate the ion rejection efficiency of the membrane, $0.10 \mathrm{~mol} / \mathrm{L} \mathrm{NaCl}, \mathrm{Na}_{2} \mathrm{SO}_{4}$ and $\mathrm{CaCl}_{2}$ solutions were prepared for DCMD experiments. The feed and the permeate temperature were kept at 50 and $20^{\circ} \mathrm{C}$, respectively. The feed and permeate flow were kept at 0.80 and $0.10 \mathrm{~m} / \mathrm{s}$, respectively. The ion rejection efficiency was calculated both according to the conductivity and the ion concentration.

\subsection{Arsenic removal experiments}

Arsenic removal experiments were carried out with aqueous $\mathrm{As}(\mathrm{III})$ and $\mathrm{As}(\mathrm{V})$ solutions, respectively. The solution $\mathrm{pH}$ was adjusted to 5.0, and the operating parameters of the DCMD process were in accordance with the ion rejection tests. Then batch concentrating experiments were carried out with initial feed arsenic $0.20 \mathrm{mg} / \mathrm{L}$. The permeate arsenic was measured during the whole concentrating process, and the experiments were shut down when the permeate arsenic concentration exceeded the maximum contaminant limit $(10 \mu \mathrm{g} / \mathrm{L})$. The arsenic rejection efficiency $R$ was calculated according to the following equation:

$R(\%)=\frac{C_{\mathrm{f}}-C_{\mathrm{p}}}{C_{\mathrm{f}}} \times 100 \%$

where $C_{\mathrm{f}}$ is the feed arsenic concentration and $C_{\mathrm{p}}$ is the permeate arsenic concentration.

In order to investigate the stability of arsenic removal efficiency, $250 \mathrm{~h}$ DCMD performance of $0.5 \mathrm{mg} / \mathrm{L} \mathrm{As}$ (III) solution and $\mathrm{As}(\mathrm{V})$ solution was carried out, respectively. The solution $\mathrm{pH}$ was adjusted to 5.0, and the operating parameters of the DCMD process were in accordance with the above concentrating experiments. In addition, the permeate flux, conductivity and the permeate arsenic were measured during the whole process.

\subsection{SEM analysis}

Both the fresh membrane and the used membrane samples were made by liquid nitrogen and dried in the oven at $50^{\circ} \mathrm{C}$. Then the membrane samples were sputter coated with gold and examined by using a Hithche S-3000 scanning electron microscope (Japan). The accelerating voltage used was $5 \mathrm{kV}$, and all samples were imaged at $5000 \times$. 


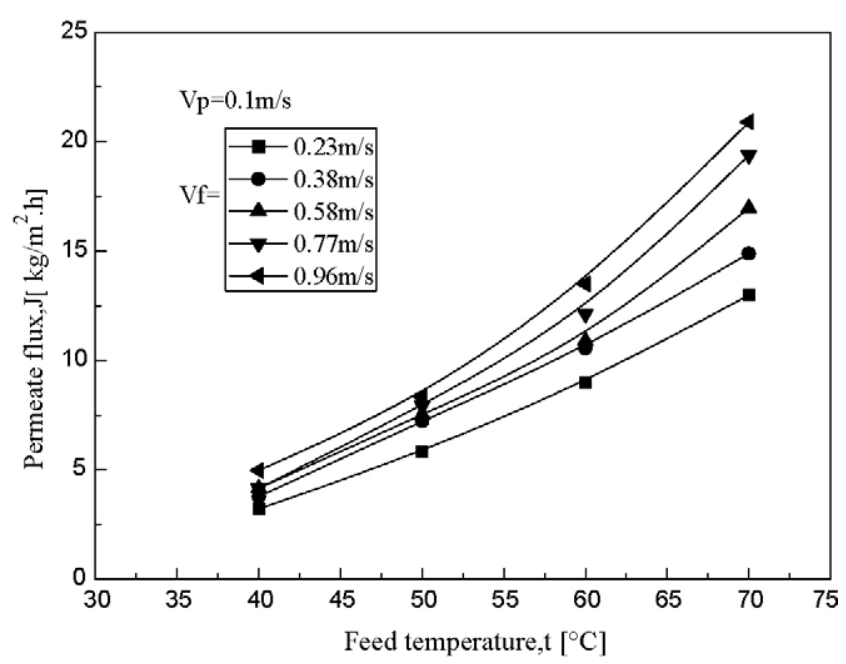

Fig. 2. Variation of permeate flux as a function of the feed temperature and feed velocity.

\section{Results and discussions}

\subsection{Permeability and ion rejection}

The permeate flux as a function of feed temperature is shown in Fig. 2. The experimental results showed that the feed temperature had a remarkable influence on the permeate flux. For example, when the feed flow rate was $0.77 \mathrm{~m} / \mathrm{s}$, the elevation of feed temperature from 40 to $70^{\circ} \mathrm{C}$ caused an increase in the permeate flux about $250 \%$. Such a sharp increase can be explained by an exponential dependence of the vapor pressure on temperature. However, the effect of the feed flow rate to the membrane permeability was not as significant as that of the feed temperature. Take $50^{\circ} \mathrm{C}$ for example, when the feed flow rate varied from 0.23 to $0.58 \mathrm{~m} / \mathrm{s}$, the permeate flux increased from 5.81 to $7.53 \mathrm{~kg} / \mathrm{m}^{2} \mathrm{~h}$ about $30 \%$. But when the feed flow increased from 0.58 to $0.96 \mathrm{~m} / \mathrm{s}$, the permeate flux only increased about $10 \%$. It is suggested that there is an optimum feed flow rate during the DCMD process [27]. A maximum permeate flux of $20.90 \mathrm{~kg} / \mathrm{m}^{2} \mathrm{~h}$ was obtained when the feed temperature reached $70{ }^{\circ} \mathrm{C}$ at $0.96 \mathrm{~m} / \mathrm{s}$ during the experiments.

Table 2 lists the results of $\mathrm{Cl}^{-}, \mathrm{SO}_{4}{ }^{2-}, \mathrm{Na}^{+}$and $\mathrm{Ca}^{2+}$ ions' removal by DCMD process. For the four kinds of ions, the removal efficiencies were all higher than $99.90 \%$, which indicated that the membrane had no selective rejection of univalent and divalent ions. The removal efficiency of $\mathrm{Cl}^{-}$at different $\mathrm{pH}$ is showed in Table 3. The removal efficiency of $\mathrm{Cl}^{-}$at $\mathrm{pH} 4.0$ and 9.0 were both $>99.90 \%$. It demonstrated that in weak alkaline and acidic mediums, the solution $\mathrm{pH}$ did not influence the ion rejection during the DCMD

Table 2

Rejection of cations and anions by DCMD

\begin{tabular}{|c|c|c|c|c|}
\hline \multirow{2}{*}{$\begin{array}{l}\text { Temperature } \\
\left({ }^{\circ} \mathrm{C}\right)\end{array}$} & \multirow[t]{2}{*}{ Ion $(0.1 \mathrm{~mol} / \mathrm{L})$} & \multirow{2}{*}{$\begin{array}{l}\text { Permeate flux } \\
\left(\mathrm{kg} / \mathrm{m}^{2} \mathrm{~h}\right)\end{array}$} & \multicolumn{2}{|l|}{ Rejection (\%) } \\
\hline & & & Conductivity & Concentration \\
\hline \multirow{4}{*}{50} & $\mathrm{Cl}^{-}$ & 7.61 & 99.99 & 99.99 \\
\hline & $\mathrm{SO}_{4}^{2-}$ & 7.59 & 99.99 & 99.98 \\
\hline & $\mathrm{Na}^{+}$ & 7.56 & 99.97 & 99.96 \\
\hline & $\mathrm{Ca}^{2+}$ & 7.53 & 99.93 & 99.94 \\
\hline \multirow{4}{*}{70} & $\mathrm{Cl}^{-}$ & 16.96 & 99.98 & 99.99 \\
\hline & $\mathrm{SO}_{4}^{2-}$ & 17.02 & 99.98 & 99.99 \\
\hline & $\mathrm{Na}^{+}$ & 16.89 & 99.99 & 99.96 \\
\hline & $\mathrm{Ca}^{2+}$ & 16.94 & 99.96 & 99.97 \\
\hline
\end{tabular}

Table 3

Effect of $\mathrm{pH}$ on $\mathrm{Cl}^{-}$rejection

\begin{tabular}{lllll}
\hline $\mathrm{pH}$ & Feed $(0.1 \mathrm{~mol} / \mathrm{L})$ & Permeate flux $\left(\mathrm{kg} / \mathrm{m}^{2} \mathrm{~h}\right)$ & \multicolumn{2}{l}{$\mathrm{Cl}^{-}$rejection $(\%)$} \\
\cline { 4 - 5 } & & Conductivity & Concentration \\
\hline 4.0 & \multirow{2}{*}{$\mathrm{NaCl}$} & 7.63 & 99.98 & 99.96 \\
9.0 & 7.59 & 99.99 & 99.98 \\
\hline
\end{tabular}

process, which was different from the results obtained from the NF and RO processes.

According to the hydrophobicity of the PVDF membrane and the mass transfer mechanism of DCMD, all inorganic cations and anions should be rejected on the feed side of the membrane. However, partial wetting phenomenon may take place. Liquid entry pressure of water (LEPw) is the minimum pressure at which water will overcome the hydrophobic forces of the membranes and will penetrate the pores. LEPw is a function of the properties of the membrane and the liquid, and the reaction between them, as given by the Laplace equation [20]:

$\mathrm{LEPw}=\frac{-2 B \gamma_{\mathrm{L}} \cos \theta}{R_{\max }}$

where $B$ is a geometric factor determined by pore structure, $\gamma_{\mathrm{L}}$ is the surface tension of the liquid, $\theta$ is the contact angle and $R_{\max }$ is the largest pore diameter. In fact, larger pores are in existence and may lead to an even lower LEPw. So the operating pressure may exceed the LEPw and result in penetration of water into the larger pores and termination of the evaporation process. Then ions could transfer directly across the lager pores to the permeate side. But only few larger pores were in existence, so the DCMD process could not be destroyed.

\subsection{Removal of As(III) by DCMD}

The permeate $\mathrm{As}$ (III) as a function of increasing feed $\mathrm{As}(\mathrm{III})$ is shown in Fig. 3.

The broken line in the graph was the maximum contaminant level $(10 \mu \mathrm{g} / \mathrm{L})$ recommended by the WHO. It could be clearly noted from the figure that the permeate As(III) was under the MCL until the feed As(III) increased to $40 \mathrm{mg} / \mathrm{L}$. And the removal efficiency could achieve $99.95 \%$. During the whole process, the permeate conductivity kept under $3.5 \mu \mathrm{S} / \mathrm{cm}$, and the permeate flux stabilized at about $7.60 \mathrm{~kg} / \mathrm{m}^{2} \mathrm{~h}$, which were not illustrated in the figure.

So far, pressure-driven membrane processes (RO and NF) have never been used for such high-concentration arsenic removal and

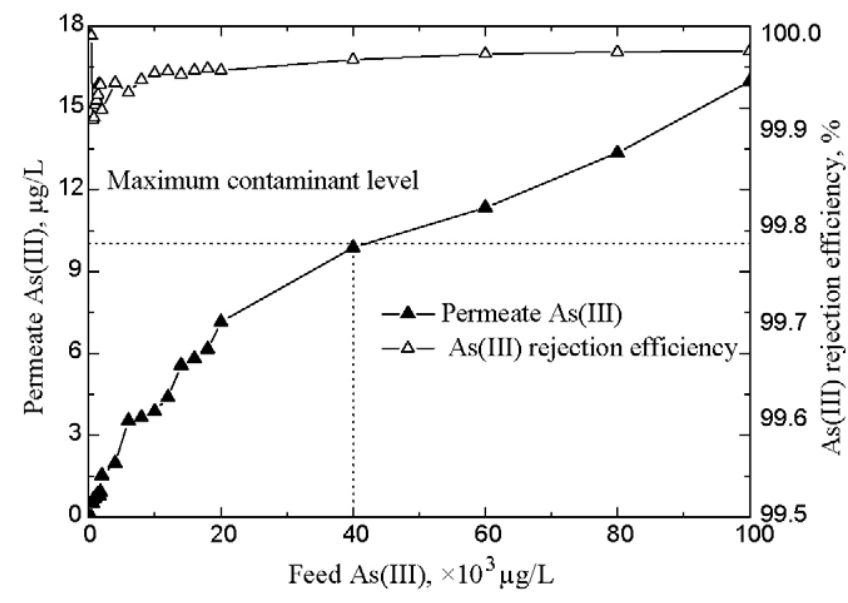

Fig. 3. Variation of permeate As(III) as a function of different feed $\mathrm{As}(\mathrm{III})$. 


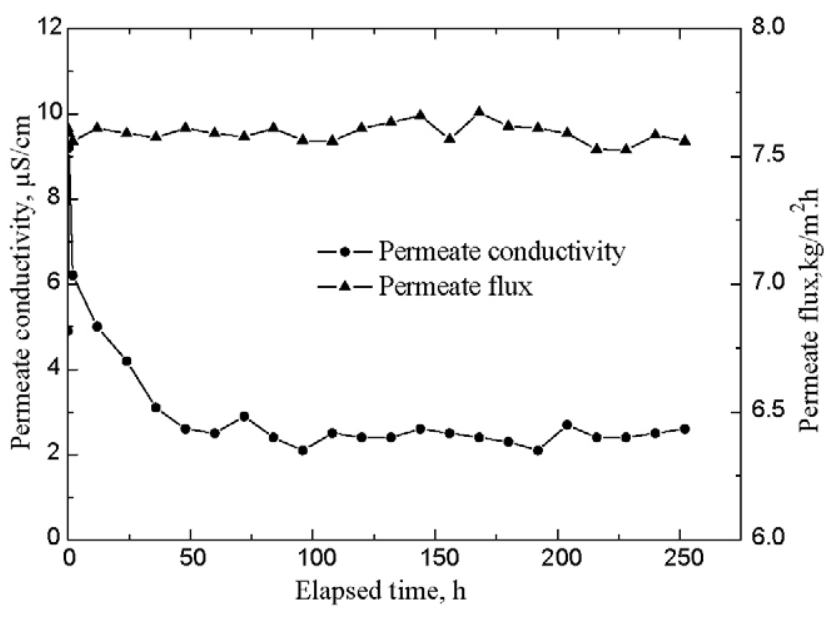

Fig. 4. Variation of permeate flux and conductivity as a function of elapsed time of the $\mathrm{As}(\mathrm{III})$ removal experiment.

the removal efficiency cannot reach up to $99.95 \%$. It was reported that $\mathrm{As}(\mathrm{III})$ removal efficiency by RO varies between 50 and $85 \%$, depending on the kinds of the membranes and the solution $\mathrm{pH}$ $[15,16]$. And in the NF process, the removal efficiency of As(III) was much lower, about 20-30\% [17-19].

The result of a $250 \mathrm{~h}$ DCMD performance of constant feed As(III) is shown in Fig. 4. The feed $\mathrm{As}$ (III) was kept at $0.5 \mathrm{mg} / \mathrm{L}$, aiming to simulate the actual arsenic-polluted groundwater in China. A sharp increase of the permeate conductivity was observed at the beginning of the performance. This phenomenon was associated with the $\mathrm{CO}_{2}$, which was not degassed completely after the acidification, crossing the membrane to the permeate side. After the initial increase, the permeate conductivity stabilized at about $3.0 \mu \mathrm{S} / \mathrm{cm}$. Moreover, there were no obvious changes of permeate flux, which showed that the PVDF membrane had a stable permeability and hydrophobicity. The measurement of the permeate As(III) during the whole process showed the permeate As(III) were all under the detection limit.

\subsection{Removal of $A s(V)$ by $D C M D$}

As seen in Table 4, As $(\mathrm{V})$ began to appear in the permeate when the feed $\mathrm{As}(\mathrm{V})$ reached $1000 \mathrm{mg} / \mathrm{L}$, and then the permeate $\mathrm{As}(\mathrm{V})$ exceeded the maximum contaminant limit when the feed $\mathrm{As}(\mathrm{V})$ reached $2000 \mathrm{mg} / \mathrm{L}$. The removal efficiency according to the permeate $\mathrm{As}(\mathrm{V})$ concentration were above $99.99 \%$. The permeate flux and conductivity were all in a stable level during the whole process.

A $250 \mathrm{~h}$ DCMD performance of $0.5 \mathrm{mg} / \mathrm{L} \mathrm{As}(\mathrm{V})$ solution was also carried out. The permeate $\mathrm{As}(\mathrm{V})$ was not detected during the process. Because the membrane module and the operating parameters of this experiment were kept the same to that of, As(III) removal experiments, and the variation of permeate flux and conductivity was basically in accordance with that of $\mathrm{As}$ (III) removal experiment. With an initial increase, the permeate conductivity kept about at $3.5 \mu \mathrm{S} / \mathrm{cm}$, and the permeate flux stabilized at about $7.50 \mathrm{~kg} / \mathrm{m}^{2} \mathrm{~h}$.

Compared with $\mathrm{As}(\mathrm{III})$, the maximum feed $\mathrm{As}(\mathrm{V})$ can reach up to $2000 \mathrm{mg} / \mathrm{L}$ when the permeate $\mathrm{As}(\mathrm{V})$ was under the maximum con- taminant limit. There was such a significant difference of removal efficiency and this difference was also found in pressure-driven processes ( $\mathrm{RO}$ and NF). RO and NF processes are negatively charged hydrophilic membrane processes and driven by the pressure. Electrostatic exclusion plays an important role in the pressure-driven process. Therefore, the main reason for the different removal efficiency of $\mathrm{As}(\mathrm{III})$ and $\mathrm{As}(\mathrm{V})$ is the different existing state between them. At pH 5-8, As(III) exists in a neutral molecular form, while $\mathrm{As}(\mathrm{V})$ exists in a negatively monovalent form. Therefore, $\mathrm{As}(\mathrm{III})$ is more difficult to be removed from water by means of pressuredriven membrane process due to the lack of electrostatic exclusion.

It is different from nanofiltration and reverse osmosis that membrane distillation is a hydrophobic membrane separation process. Thus, theoretically all the $\mathrm{As}(\mathrm{III})$ and $\mathrm{As}(\mathrm{V})$ ions should be rejected to the feed side. However, the experimental results were not in accordance with the theoretical analysis. That is because partial wetting phenomenon still exists just as mentioned in the previous experiments. The existing larger pores will lead to a lower LEPw, where the membrane has a hydrophilic property. So As(III) and $\mathrm{As}(\mathrm{V})$ ions can directly transfer across the membrane to the permeate through the pores. Furthermore, the PVDF capillary membrane used in the paper is negatively charged in the solution, thus, compared with $\mathrm{As}(\mathrm{V}), \mathrm{As}(\mathrm{III})$ is more difficult to be removed from water due to the lack of electrostatic exclusion.

Generally speaking, compared with pressure-driven membrane processes, DCMD has higher removal efficiency of both arsenite and arsenate.

\subsection{SEM analysis}

Electron micrographs of PVDF membranes taken before and after arsenic removal experiments are shown in Fig. 5. It can be seen from the micrographs that the morphology of both inner surface and the section changed after the experiments.

In a previous study, the membrane morphology changes were found on PP membranes [28]. An increase in the values of various morphology parameters (pore area, pore length, pore breadth, etc.) was observed after the water contact experiments. This increase was attributed to the pore intrusion by the liquid meniscus, which leads larger pores to spread, causing the neighboring smaller pores to decrease in size and possibly close completely.

For the PVDF membrane, the quantities of micro-pores in visual decreased after the experiments (Fig. 5, $\mathrm{A}_{2}$ and $\mathrm{A}_{3}$ ). A large amount of pores decreased in size and some even closed completely. But no significant pore spreading was observed, which was different from the results obtained from PP membranes. However, a slight increase of micro-pores, which cannot be detected visually under low magnification factor, may occur in the experiments.

The series B in Fig. 5 shows the changes of the membrane section. It can be seen that the bottom of the finger-like pores were smooth before the experiments, while after the removal experiments, the bottom of the finger-like pores were fragmentized both adjacent to the inner skin (Fig. 5, $B_{2}$ ) and to the outer skin (Fig. 5, $B_{1}$ ). The changes were directly found at the bottom of the finger-like pores, which indicated that physical force was the main reason. During the frequent mass transfer processes, water vapor transferred from finger-like pores to sponge pores, like transferring from a wide

Table 4

Permeate $\mathrm{As}(\mathrm{V})$ at different feed $\mathrm{As}(\mathrm{V})$

\begin{tabular}{|c|c|c|c|c|c|}
\hline Feed $\mathrm{As}(\mathrm{V})$ concentration $(\mathrm{mg} / \mathrm{L})$ & $<1000$ & 1200 & 1500 & 1800 & 2000 \\
\hline Permeate $\mathrm{As}(\mathrm{V})$ concentration $(\mu \mathrm{g} / \mathrm{L})$ & - & 2.92 & 4.39 & 6.39 & 10.92 \\
\hline $\mathrm{As}(\mathrm{V})$ removal efficiency (\%) & & $>99.99$ & $>99.99$ & $>99.99$ & $>99.99$ \\
\hline
\end{tabular}



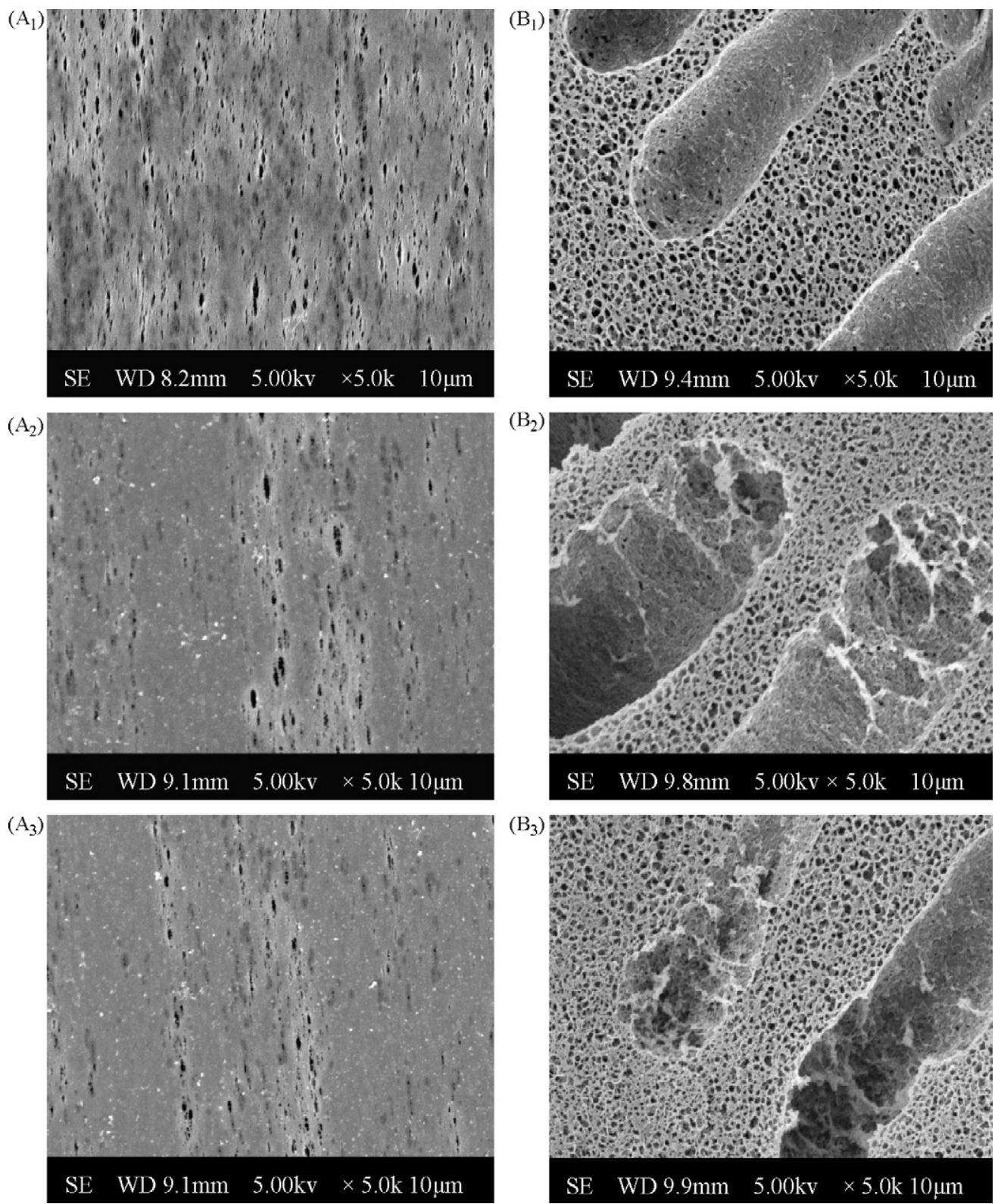

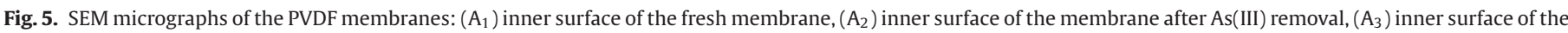

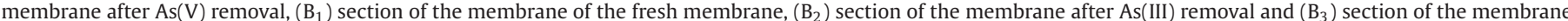
after $\mathrm{As}(\mathrm{V})$ removal.

channel to much smaller pores. So at the bottom of the finger-like pores, the transfer resistance became larger and the collision of water vapor may be the main reason for the phenomenon.

Permeability and ion rejection tests were performed on used PVDF membranes and the result showed that the membranes' permeability and hydrophobicity were not changed after such morphology changes.

\section{Conclusions}

In the present work, self-made PVDF membranes were used for the arsenic removal. The following conclusions were obtained:

(1) The PVDF membrane had high rejection of inorganic cations and anions. The rejections of the ions mentioned were all above $99.90 \%$, which were independent of the solution $\mathrm{pH}$.
(2) It was found that DCMD process had higher removal efficiency of both $\mathrm{As}(\mathrm{III})$ and $\mathrm{As}(\mathrm{V})$ than pressure-driven membrane processes (reverse osmosis and nanofiltration). And the removal efficiencies were all above 99.95\%. Furthermore, DCMD exhibited a removal ability of high-concentration arsenic solutions. The experimental results indicated that the permeate As(III) and $\mathrm{As}(\mathrm{V})$ were below the maximum contaminant limit $(10 \mu \mathrm{g} / \mathrm{L})$ until the feed $\mathrm{As}(\mathrm{III})$ and $\mathrm{As}(\mathrm{V})$ increased to 40 and $2000 \mathrm{mg} / \mathrm{L}$, respectively.

(3) The results of a $250 \mathrm{~h}$ simultaneous DCMD performance of $0.5 \mathrm{mg} / \mathrm{L} \mathrm{As}$ (III) solutions showed that the PVDF membrane had a stable As (III) rejection. The permeate As(III) was not detected during the whole process.

(4) Membrane morphology changes were observed after the removal experiments. But the permeability and the salt rejection did not change. 


\section{Acknowledgements}

This work was supported by the National Key Technologies R\&D Program (Grant no. 2006BAD01B02-02, Grant no. 2006BAJ08B00) and the National Natural Science Foundation of China (Grant no. 50678169).

\section{References}

[1] National Research Council, Arsenic in Drinking Water: 2001 Update, Nationa Academy Press, Washington, DC, 2001.

[2] P.L. Smedley, D.G. Kinniburgh, A review of the source, behavior and distribution of arsenic in natural waters, Appl. Geochem. 17 (2002) 517-568.

[3] World Health Organization, World Health Organization Guidelines for Drinking Water Quality. Health Criteria and Other Supporting Information, 2nd ed. WHO, Geneva, Switzerland, 1996.

[4] F.F. Peng, P. Di, Removal of arsenic from aqueous solution by adsorbing colloid flotation, Ind. Eng. Chem. Res. 33 (1994) 922-928.

[5] F.G.A. Vagliasindi, M.M. Benjamin, Arsenic removal in fresh and non-preloaded ion exchange packed bed adsorption reactors, Water Sci. Technol. 38 (1998) 337-343.

[6] D. Mohan, C.U. Pittman, Arsenic removal from water/wastewater using adsorbents, J. Hazard. Mater. 142 (2007) 1-53.

[7] M.C. Shih, An overview of arsenic removal by pressure-driven membrane processes, Desalination 172 (2005) 85-97.

[8] C.L. Chuang, M. Fan, M. Xu, R.C. Brown, S. Sung, B. Saha, C.P. Huang, Adsorption of arsenic(V) by activated carbon prepared from oat hulls, Chemosphere 61 (2005) 478-548.

[9] S. Ouvrard, M.O. Simonnot, P. Donato, M. Sardin, Diffusion-controlled adsorption of arsenate on a natural manganese oxide, Ind. Eng. Chem. Res. 41 (2002) 6194-6199.

[10] P.K. Dutta, A.K. Ray, V.K. Sharma, F.J. Millero, Adsorption of arsenate and arsenite on titanium dioxide suspensions, J. Colloid Interface Sci. 278 (2004) 270-275.

[11] D. Pokhrel, T. Viraraghavan, Arsenic removal from an aqueous solution by a modified fungal biomass, Water Res. 40 (3) (2006) 549-552.
[12] H.S. Altundogan, S. Altundogan, F. Tumen, M. Bildik, Arsenic removal from aqueous solutions by adsorption on red mud, Waste Manage. 20 (2000) 761-767.

[13] F.S. Zhang, H. Itoh, Iron oxide-loaded slag for arsenic removal from aqueous system, Chemosphere 60 (2005) 319-325.

[14] S. Chakravarty, V. Dureja, G. Bhattacharyya, S. Maity, S. Bhattacharjee, Removal of arsenic from groundwater using low cost ferruginous manganese ore, Water Res. 36 (2002) 625-632.

[15] R.Y. Ning, Arsenic removal by reverse osmosis, Desalination 143 (2002) 237-241.

[16] M. Kang, M. Kawasaki, S. Tamada, Effect of $\mathrm{pH}$ on the removal of arsenic and antimony using reverse osmosis membranes, Desalination 131 (2000) 293-298.

[17] K. Kosutic, L. Furac, Removal of arsenic and pesticides from drinking water by nanofiltration membranes, Sep. Purif. Technol. 42 (2005) 137144.

[18] Y. Sato, M. Kang, Performance of nanofiltration for arsenic removal, Water Res. 36 (2002) 3371-3377.

[19] S. Jia, B. Dong, Study of arsenic removal by nanofiltration and its application in China, Desalination 204 (2007) 374-379.

[20] K.W. Lawson, D.R. Lloyd, Membrane distillation, J. Membr. Sci. 124 (1997) 1-25.

[21] S.T. Hsu, K.T. Cheng, J.S. Chiou, Seawater desalination by direct contact membrane distillation, Desalination 143 (2002) 279-287.

[22] K.B. Petrotos, H.N. Lazarides, Osmotic concentration of liquid foods, J. Food Eng. 49 (2001) 201-206.

[23] M. Tomaszewska, Concentration and purification of fluosilicic acid by membrane distillation, Ind. Eng. Chem. Res. 39 (2000) 3038-3041.

[24] M. Gryta, K. Karakulski, The application of membrane distillation for the concentration of oil-water emulsions, Desalination 121 (1999) 23-29.

[25] T.G. Zakrzewska, M. Harasimowicz, A.G. Chmielewski, Membrane processes in nuclear technology-application for liquid radioactive waste treatment, Sep. Purif. Technol. 22 (2001) 617-625.

[26] E. Curcio, A. Criscuoli, E. Drioli, Membrane crystallizers, Ind. Eng. Chem. Res. 40 (2001) 2679-2684

[27] M. Gryta, M. Tomaszewska, A.W. Morawski, A capillary module for membrane distillation process, Chem. Pap. 54 (2000) 370-374.

[28] A.M. Barbe, P.A. Hogan, R.A. Johnson, Surface morphology changes during initial usage of hydrophobic microporous polypropylene membranes, J. Membr. Sci. 172 (2000) 149-156. 